\title{
Cultivating Informatics Competencies in a Community of Practice
}

\author{
Amy J. Barton, PhD, RN
}

\begin{abstract}
To move the healthcare industry into the 21st century, nurses must become savvy in the use of informatics to provide optimal care to their patients. However, the relatively few formal nursing informatics programs that exist across the country are simply not adequate to meet the demands of both new and existing nurses. Informatics competencies must be incorporated into nursing curricula at entry-level and via staff development to provide a ready workforce. Creative faculty development strategies that capitalize on the concept of faculty as a community of practice are required to incorporate informatics competencies into nursing curricula. Key words: curricula, faculty, informatics, information technology, nursing education
\end{abstract}

$S^{1}$ INCE the proliferation of computers, there has been much discussion about what the expected competency of nurses should be to work with the various forms of information and communication technologies in healthcare delivery today. Computer literacy or technology literacy has become a significant issue in today's nursing profession, and is especially significant in education as we strive to prepare nurses for current and future healthcare systems. Two significant publications have highlighted the current importance of informatics competencies for nurses. First, in the revised Scope of Practice for Nursing Informatics, ${ }^{1}$ information technology competencies have been identified across all educational levels of nursing, recognizing that it is not the sole responsibility of the nurse informaticist to be skilled in using this technology. Informatics competencies should be integrated into the nursing curriculum. Second, in response to the 2001 report from the Institute

From the University of Colorado at Denver and Health Sciences Center School of Nursing.

Corresponding author: Amy J. Barton, PbD, RN, University of Colorado at Denver and Health Sciences Center School of Nursing, 4200 E Ninth Ave, Box C288-55, Denver, CO 80262 (e-mail: amy.barton@uchsc.edu). of Medicine, Crossing the Quality Chasm, an interdisciplinary summit was convened to discuss its implications for health professions education. In its report, Health Professions Education: A Bridge to Quality, the institute articulated the following vision:

All health professionals should be educated to deliver patient-centered care as members of an interdisciplinary team, emphasizing evidence-based practice, quality improvement approaches, and informatics. $^{2}$

The committee focused on the utilization of information. They believe that through informatics there is potential for reduction of errors, better management of knowledge and information, enhanced decision making, and communication. Reduction of errors can occur through the effective use of information systems and provider order entry. Management of knowledge and information can be facilitated by online and on-site databases as well as through an electronic medical record. Decision making can be enhanced through computerized decision support systems. Finally, communication can be enhanced through patients and providers sharing access to electronic medical records and using e-mail to further exchange information. 
Computer and information literacy have become significant to professional nursing. The National League for Nursing Academic Committee (NLNAC) defined technology literacy as "the ability to effectively use information technology systems, communication technologies, and sophisticated information management systems." This also includes the ability to apply knowledge and skills in the safe use of medical devices in nursing practice. ${ }^{3}$ The NLNAC requires educational programs to ensure within each level's parameters of competency that graduates are "educated to acquire wisdom, ethical qualities, and skills, including the following:

- Technical and interpersonal competencies important to performance after graduation

- Communications, computation, and technological literacy that enable the gaining and applying of new knowledge and skills as needed.

- The ability to arrive at informed clinical judgments, that is, to effectively define problems, gather and evaluate relevant information, and develop solutions to manage multiple problems ..."

The American Association of Colleges of Nursing (AACN) identified essential clinical resources for undergraduate and graduate nursing education. ${ }^{4}$ It specifically identified learning opportunities concerning managing health-related data and using information technologies to provide nursing care. In addition, 2 task forces identified specific competencies for a new role and a new degree program. In a working paper describing the proposed new role of clinical nurse leader, core competencies of nursing technology and resource management as well as information and healthcare technologies are recommended. ${ }^{5}$ In its position statement describing the practice doctorate in nursing, the AACN identified "utilization of technology and information for the improvement and transformation of healthcare" as 1 of the 7 essential areas of content. ${ }^{6}$

A random sample of members from the American Organization of Nurse Executives were surveyed to identify technology skills and information literacy required of new nurses entering the workforce. ${ }^{7}$ Computer skills rated as critical for new nurses included using e-mail effectively, operating Windows applications, searching databases, and knowing nursing-specific software for charting and medication administration. A recent survey of school of nursing deans revealed that more emphasis is placed on computer literacy versus information literacy in baccalaureate nursing programs. ${ }^{8}$ Further, "data indicate a gap exists in the knowledge needed by nursing faculty to prepare nurses to be skilled in information technology and its use to manage clinical information in daily practice." $8(\mathrm{p} 347)$

A national survey of RNs was conducted to determine information literacy competencies with respect to evidence-based practice. ${ }^{9}$ RNs reported that their most frequent source of information was a peer; most did not search information resources to gather practice information; and only $27 \%$ of respondents had any instruction in using electronic databases. Clearly, a substantial gap exists between expectations of nurse executives, curriculum in schools of nursing, and competencies among RNs.

Simpson asserts that:

“...nursing-both service and education-faces significant challenges today and in the future, from service's managed care-imposed information burden and nursing shortage, to education's budget constraints, declining enrollments, competition for specialty sites, and aging faculty. Survival of the profession rests on developing collaborative models that utilize the best in each arena, while maximizing the shared resources. The key enabler of such collaboration is technology."

He suggests that leveraging technology (online courses, Internet networks, telehealth, and e-health tools) in both the education and service settings shows great potential for meeting these challenges. ${ }^{10}$

Traditional faculty development approaches provide resources to members as individuals or in small groups to pursue largely self-identified goals or to maintain competence in a particular specialty area of 
expertise. The curricular reform required to incorporate the required informatics competencies requires much more than group seminars, external consultants, and individual learning. The use of social learning theory and the transformation of the faculty into a community of practice are proposed as strategies to meet informatics competencies.

\section{COMMUNITIES OF PRACTICE}

"Communities of practice are groups of people who share a concern, a set of problems, or a passion about a topic, and who deepen their knowledge and expertise in this area by interacting on an ongoing basis." $11(\mathrm{p} 4)$ This definition fits with nursing faculties since they are passionate and share a concern with delivering a high-quality product to produce the next generation of healthcare providers. They have expertise in a variety of independent areas, yet come together to direct and deliver the curriculum. The subsequent synergy creates an added value that not only capitalizes on personal development but also connects faculty to the organization and the broader professional community.

"A community of practice is a unique combination of three fundamental elements: a domain of knowledge, which defines a set of issues; a community of people who care about this domain; and the shared practice that they are developing to be effective in their domain."11(p27) The domainnursing curriculum-is the common ground that draws the community together. The community members are faculty who deliver the curriculum and create "the social fabric of learning."11(p28) Finally, the practice is "a set of frameworks, ideas, tools, information, styles, language, stories, and documents that community members share." ${ }^{(\mathrm{p} 29)}$ The goal of this article is to illustrate how this framework and tools can be used among faculty to incorporate informatics competencies into the curriculum to produce effective health professions graduates of the future.

\section{SEVEN PRINCIPLES FOR CULTIVATING COMMUNITIES OF PRACTICE}

Wenger and colleagues identify 7 principles for cultivating communities of practice: design for evolution, open a dialogue between inside and outside perspectives, invite different levels of participation, develop both public and private community spaces, focus on value, combine familiarity and excitement, and create a rhythm for the community. ${ }^{11}$ In this section, each principle is discussed to illustrate how faculties can be transformed into communities of practice and successfully incorporate a specific competency, information literacy, into nursing curriculum.

\section{Design for evolution}

Nursing faculties are at an unprecedented stage for transformation. Traditionally, faculties have been a stable workforce. The graying of the faculty and subsequent retirements associated with this phenomenon create an incredible opportunity to move the informatics agenda forward. The concept of evolution requires a dynamic force that facilitates change and free exchange of ideas. The challenge to deans is to facilitate this workforce evolution in a manner that attracts self-motivated faculty who are attracted to an energetic and vibrant work environment. The incorporation of information literacy as a curricular thread can serve as a catalyst to facilitate change and move the evolutionary process forward.

Faculty are already familiar with many of the information literacy competencies as they relate to their own research. Creating an appropriate workforce requires translating these competencies into practice and working with students to become savvy in evidence-based practice.

\section{Open a dialogue between inside and outside perspectives}

Wenger and colleagues suggest, "Good community design requires an understanding of the community's potential to develop and steward knowledge, but it often takes an 
outside perspective to help members see the possibilities."11(p54) To incorporate informatics competencies into both undergraduate and graduate curricula, an outside consultant may be required to present the big picture and provide concrete examples of how to weave the new tools into existing courses. In addition, experts from the practice environment can share their use of computer and information technologies and identify key links to facilitate students' development prior to their entry into the workforce. Innovative partnerships between schools of nursing and information systems vendors can help propel faculty into the technologies available within the practice dimension.

\section{Invite different levels of participation}

One of the greatest advantages of using the communities of practice framework for faculty development is that it does not require the same level of participation of all parties. Rather, it capitalizes on the realities of human nature and continues to recognize each individual as part of the community, regardless of his or her participation. Communities of practice actually encourage different levels of participation. Four levels, which may be visualized as concentric circles, have been identified as follows: core group, active participants, peripheral participants, and the surrounding community.

The core group consists of the innovators who direct activities and actively participate in discussion and debate. These are faculty who come to meetings with wireless technology in hand, ready to search for the latest evidence. The active participants are those who choose to attend meetings and participate in discussions, but not as intensely or regularly as the core group. For example, these may recognize the importance of evidence-based practice and assign students pertinent activities, but may not necessarily be truly engaged themselves. A large portion of community members are peripheral and rarely participate. Some remain peripheral because they feel that their observations are not appropriate for the whole or carry no authority. For example, clinical instructors often rely on direction from the course coordinator and may not feel free to implement information literacy activities in clinical rotations. Others do not have the time to contribute more actively. Fully funded researchers may be dedicated to their projects and not have the flexibility to contribute to the efforts of the faculty as a whole. Finally, outside these 3 main levels are people surrounding the community who are not members but who have an interest in the community, including customers, suppliers, and "intellectual neighbors." Pertinent to nursing are those agencies that host clinical experiences for students and may not have the infrastructure to support evidence-based practice for their own staff, let alone the student population.

The concept of movement between levels is important to development of a strong community of practice. A variety of commitments may restrict active participation of members at various times. However, the key is not to isolate those on the periphery, but rather to use informal mechanisms to keep them in the loop and reinforce the work of the broader community. Both physical and electronic resources can be used to help maintain connection with those in the periphery. An electronic bulletin board that allows for anonymous responses can be helpful in gauging community reaction. Casual hallway conversations can also be used to maintain movement in a positive direction.

\section{Develop both public and private community spaces}

One characteristic of communities is that they have public events where members can gather for social and/or business exchange. However, many exchanges or events occur "behind the scenes" and are dependent on the interpersonal relationships that members of the community develop among themselves. The key to using the communities of practice model in adopting informatics competencies 
among faculty is to recognize the limits of public events. It is important to have faculty champions who can work the informal networks between public events in order to have continuity and maintain momentum. Leaders in the adoption of technological innovation can host informal sessions for faculty or provide guest lectures for faculty who are not as comfortable sharing the technology with students.

\section{Focus on value}

Value is a keystone of community development. Community members must feel that their work is of value and their individual contributions are valuable to the whole. The incorporation of informatics competencies is a natural fit since use of these tools and technologies can facilitate added value and increase efficiency in everyday work. Using the office management technology, exploring student learning competencies through simulation, or teaching in an asynchronous online environment permits individual recognition of relative value and enhances the community's ability for its true potential value to emerge. It is important for the faculty champions to include others in the development of scholarly papers or projects to contribute to advancement of the discipline.

\section{Combine familiarity and excitement}

Establishing an infrastructure to facilitate exchange is required in any community of practice. Whether these be standard committee meetings, seminars, or Web-based discussion groups, familiar forums are necessary to provide a sense of comfort to community members. At the same time, use of external experts or innovative approaches can provide a level of excitement to keep the innovation moving forward and compel members at the periphery to participate more fully. To implement information literacy into the curriculum, one may consider planning a kick-off celebration with an external speaker, followed by a series of work sessions that are already incorporated into faculty life.

\section{Create a rhythm for the community}

It is important for any development activity to be appropriately paced so that faculty are not overwhelmed. Yet, it needs to occur at a regular enough basis so that faculty can see progress as the agenda moves forward. A comfortable rhythm that facilitates movement without creating undue anxiety is most effective. To implement information literacy competencies, it might be more comfortable to begin with a graduate program, and then move to an undergraduate program. Within each program, it is important to identify core courses that lend themselves to the innovation. Working with the faculty assigned to those courses will help "institutionalize" implementation and move it beyond the few champions that may exist.

\section{DEVELOPING A COMMUNITY OF PRACTICE}

Planning a community of practice involves the following: determining the intent of the community, defining the domain, building the case for action, identifying potential coordinators and thought leaders, and connecting potential members. ${ }^{11}$ Wenger and colleagues propose 4 strategic intents: helping communities, best-practice communities, knowledge-stewarding communities, and innovation communities. It is possible that faculties will begin using informatics to facilitate a best-practice community but then transform to an innovation community where all members develop and contribute advancements and originality. The case for action has already been established by the professional organizations (NLNAC and AACN) that guide nursing curriculum. The success of the community will rely on key thought leaders and a coordinator. "Effective community leaders typically are well respected, knowledgeable about the community's domain, well connected to other community members..., keen to help develop the community's practice, relatively good communicators, and personally interested in community leadership."11(pp80-81) 
To move the healthcare industry into the 21st century, nurses must become savvy in the use of informatics to provide optimal care to their patients. As McBride states, "The focus in nursing practice and education must be on achieving information liter- acy, not merely computer literacy..."12 Using the communities of practice concept, creative strategies to incorporate informatics competencies will facilitate the movement of faculties toward communities of innovation.

\section{REFERENCES}

1. American Nurses Association. Scope and Standards of Nursing Informatics Practice. Washington, DC: American Nurses Publishing; 2001.

2. Institute of Medicine. Health Professions Education: A Bridge to Quality. Washington, DC: The National Academy of Sciences; 2003.

3. Felton G, Abbe S, Gilbert C, Ingle JR. What is an interim report? Why is it used? Nurs Health Care Perspect. 2000;21(3):147.

4. American Association of Colleges of Nursing. Essential Clinical Resources for Nursing's Academic Mission. Washington, DC: American Association of Colleges of Nursing; 1999.

5. American Association of Colleges of Nursing. Working paper on the role of the clinical nurse leader. June 2004. Available at: http://www.aacn.nche.edu/ Publications/WhitePapers/ClinicalNurseLeader.htm. Accessed August 11, 2005.

6. American Association of Colleges of Nursing. Position statement on the practice doctorate in nursing. October 2004. Available at: http://www.aacn.
nche.edu/DNP/DNPPositionStatement.htm. Accessed August 11, 2005.

7. McCannon M, O'Neal PV. Results of a national survey indicating information technology skills needed by nurses at time of entry into the work force. $J$ Nurs Educ. 2003;42:337-340.

8. McNeil BJ, Elfrink VL, Bickford CL, et al. Nursing information technology knowledge, skills, and preparation of student nurses, nursing faculty, and clinicians: a U.S. survey. J Nurs Educ. 2003;42:341-349.

9. Pravikoff DS, Pierce ST, Tanner A. Evidence-based practice readiness study supported by academy nursing informatics expert panel. Nurs Outlook. 2005;53:49-50.

10. Simpson RL. Technology-enabling the service education partnership. Nur Adm Q. 2001;26(1):87-91.

11. Wenger E, McDermott R, Snyder WM. Cultivating Communities of Practice. Boston: Harvard Business School Press; 2002.

12. McBride $A B$. Nursing and the informatics revolution. Nurs Outlook. 2005;53:183-191. 